\title{
Speech act theory as an approach to interpret Gospel narratives
}

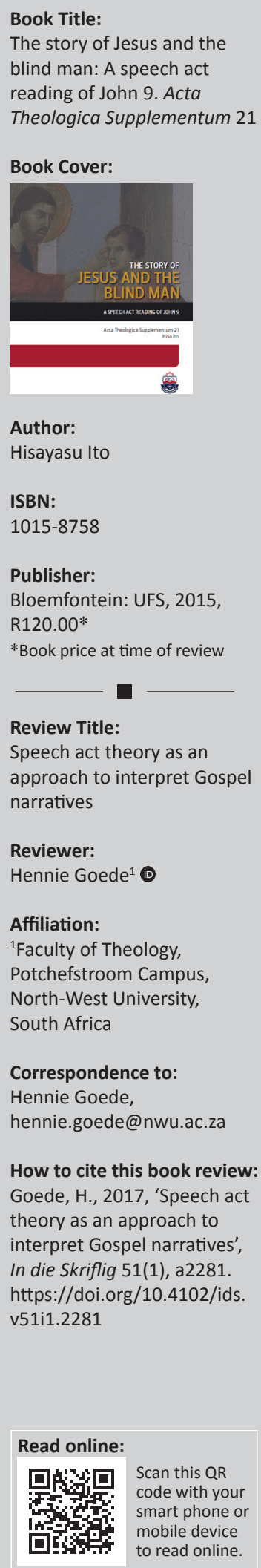

The author, Professor Hisa Ito from the Ritsumeikan University in Kyotot City in Japan, studied a Master of Divinity in the United States of America before completing his doctoral thesis at the University of the Free State, Bloemfontein, South Africa in 2000. Within the broader discourse regarding the complementary relationship between literary criticism and historical criticism, Ito endeavoured to show that an integrated approach of the two perspectives is possible and advantageous. He did so through utilising the findings of historical criticism in literary criticism, finding a scholarly environment receptive to new methodologies in South Africa.

This publication represents a reworking of Ito's thesis 15 years after the submission of the latter, although the main thrust remains the same. Chapter 1 presents introductory material on previous studies on John 9, providing the basis for the need for a detailed analysis of John 9 from a pragmatic perspective with special emphasis on irony (p. 6). The purpose of the study is formulated as follows:

... to analyse, in detail, the text of John 9 from a speech act perspective, with the emphasis on how language functions in order to determine whether or not such an analysis leads to acceptable and valid results as an interpretation of the text (p. 8).

The author's expectation of the study was that it '[...] could possibly yield a new understanding of the way in which gospel narratives such as John 9 are carefully constructed by the implied author for the implied reader' (p. 8). This expectation was based on '[...] a new understanding of how communication takes place in the text from a linguistic perspective', and the successful application of speech act theory to texts in literature.

In chapter 2 the author describes in detail the methodology that he applied in the study. This methodology focuses on speech act theory, but also incorporates related approaches to the extent that they augment speech act theory (p. 35). The researcher also provides insight into the advantages and disadvantages of the methodology he employed in the study. Chapter 3 contains a contextual survey of John 9 based on appropriateness conditions required for successful conversation. His aim with this approach is to find the most plausible contexts for John 9 as an example of an attempt to combine historical and literary approaches (p. 60).

Chapter 4 is the heart of the research presented in the publication, comprising $72 \%$ of its length in pages (excluding the bibliography). Ito presents his analysis of John 9 with great and admirable rigour. The analysis combines speech act theory with other approaches and his general point of departure, namely making use of historical and literary approaches to supplement his understanding of the text, radiates clearly from his analysis. The detailed nature of the analysis does not make for easing reading, but the scholar interested in the Gospel of John and the application of alternative approaches to its interpretation, will certainly appreciated the author's effort. Chapter 5 contains a summary of the analysis and the author's conclusions based on the same, dealing with aspects such as the use of interpersonal and textual rhetorics, symbolism, irony, and suffering in John 9. These will interest specialist scholars. Ito also evaluates the method he used in this study (p. $473 \mathrm{ff}$.), commenting positively on speech act analysis as a useful exegetical approach, especially when dealing with narrative texts and used in tandem with other approaches. He also identifies certain shortcomings in the method, especially the improvements to the taxonomy for the classification of speech acts (p. 475).

The question remains whether the author achieved his goal with this publication as quoted above. That he succeeded in producing a detailed analysis of John 9, is beyond question. As to whether the expectation of the author was met, I do have some doubts. His analysis certainly clarified and elucidated certain aspects of previous investigations of John 9, but a clear description of the value

Copyright: (C 2017. The Authors. Licensee: AOSIS. This work is licensed under the Creative Commons Attribution License. 
added to interpretation of John 9 by way of this approach is lacking (with the exception of the findings on irony). A more focused delineation of future research flowing from the study, would also be helpful, especially to young scholars interested in the Johannine corpus or the approach designed and applied by Ito. These points of criticism, however, are minor, and I would certainly recommend this publication to scholars in the field. 